\title{
Effects of tumor biobank storage on polysome stability
}



\author{
Fernanda C. S. Lupinacci, Elisa N. Ferreira, Martin Roffe, Hermano M. Bellato, Dirce M. Carraro and \\ Glaucia N. M. Hajj (D)
}

\begin{abstract}
Background: Human biological material has become an important resource for biomedical research. Tumor Biobanks are facilities that collect, store and distribute samples of tumor and normal tissue for further use in basic and translational cancer research. mRNA-translation has been demonstrated to modulate protein levels and is considered a fundamental post-transcriptional mechanism of gene expression regulation. Thus, determining translation efficiencies of individual mRNAs in human tumors may add another layer of information that contributes to the understanding of tumorigenic pathways. To analyze the RNAs actively engaged in translation, RNAs associated with ribosomes (polysomes) are isolated, identified and compared to total RNA. However, the application of this technique in human tumors depends on the stability of the polysomal structure under Biobank storage conditions that usually consists of ultra-low temperature. Since the effect of freezing on the stability of the polysomal structure in stored tumor samples is not known, it is essential to evaluate this factor in the frozen samples, validating the use of biobank samples in studies of translational efficiency.
\end{abstract}

Methods: Xenograft tumors were divided in two parts, half was subject to immediate processing, and half was frozen for posterior analysis. Both parts were subject to polysomal separation, RNA extraction and identification through RNAseq.

Results: It was possible to successfully extract and identify total and polysomal RNA from both fresh and frozen tumoral tissue. The quantification of the polysome profile indicated no difference in the translational efficiency estimated in fresh versus frozen tissue. Gene expression data from the fresh versus frozen tissues were compared and the correlation between the polysome associated fresh $\mathrm{x}$ frozen $(R=0,89)$ and total fresh $\mathrm{x}$ frozen $(0,90) \mathrm{mRNAs}$ was calculated. No difference was identified between the two conditions.

Conclusions: We demonstrated that tissue freezing does not affect the polysomal structure, consequently validating the viability of the use of biobank stored tissue for polysome associated RNA analysis.

Keywords: Polysomes, Polysomal stability, Translation, Polysomal RNA

\section{Background}

Human biological material obtained through common diagnostic procedures or surgery has become an important resource for biomedical research. In oncology, tumor tissue samples represent a precious tool for both clinical and experimental research. Tumor banks are facilities that are organized to collect, store and distribute

\footnotetext{
* Correspondence: ghajj@accamargo.org.br

International Research Center, AC Camargo Cancer Center and National Institute of Science and Technology in Oncogenomics and Therapeutic Innovation, Rua Taguá 440, São Paulo, Brazil
}

samples of tumour and normal tissue for further use in fundamental and translational cancer research $[1,2]$. The A.C.Camargo Cancer Center biobank was estabished in 1997, and is considered as a national reference for stored tissue samples and isolated macromolecules.

It is known that gene expression is modulated at multiple levels and each layer dynamically contributes to the final proteome [3]. In particular, mRNA-translation has been suggested to modulate protein levels to a similar extent as transcription and thus it is considered a fundamental post-transcriptional mechanism affecting the proteome

(c) The Author(s). 2019 Open Access This article is distributed under the terms of the Creative Commons Attribution 4.0 International License (http://creativecommons.org/licenses/by/4.0/), which permits unrestricted use, distribution, and 
$[4,5]$. In addition, mRNA translation can be selectively modulated, thus changing the levels of specific subsets of proteins $[6,7]$. Thus, determining translation efficiencies of individual mRNAs in human tumors may add another layer of information that contributes to a more complete understanding of tumorigenic pathways. To analyze the RNAs actively engaged in translation, the population of mRNAs associated to ribosomes, in a structure called polysome, can be experimentally isolated and identified through RNAseq or microarray technologies $[8,9]$. However, the stability of the polysomal structure in the conditions used to store samples (ultra-low temperature) in Biobanks must be determined in order to allow for the use of this technique in biobank samples. To our knowledge, the determination of polysome stability in tissues has not been evaluated. Thus, in this work we analyzed the polysomal stability in fresh and frozen xenograft tumors, evaluating both translational rates and gene expression profiles.

\section{Methods}

\section{Cell culture}

LN-229 cells (ATCC CRL-2611) were maintained in DMEM High Glucose medium (Thermo) with $10 \%$ fetal bovine serum (Thermo) in a humid incubator at $37^{\circ} \mathrm{C}$ and $5 \% \mathrm{CO}_{2}$.

\section{Injection of LN-229 cells into nude mice for tumor} formation

LN-229 cells (5 million cells/mice) were injected into the flank of three nude mice. After 4 weeks, when the tumors achieved $1 \mathrm{~cm}^{3}$, the animals were euthanized and the tumors were removed and divided in two: half was lysed immediately and half was frozen in liquid nitrogen. After 15 days of freezing, these other halves of the tumors were lysed. This experiment was approved by the Animal Ethics Committee (057/13).

\section{Isolation of polysomes \\ Tissue lysis}

Tissues were lysed with $20 \mathrm{mM}$ Tris- $\mathrm{HCl}$ buffer $\mathrm{pH} 7.5$ (Sigma), $100 \mathrm{mM} \mathrm{KCl}$ (Sigma), $10 \mathrm{mM} \mathrm{MgCl} 2$ (Sigma), 1\% Triton X-100 (Sigma), $1 \mathrm{mM} \mathrm{DTT} \mathrm{(Sigma),} 100 \mu \mathrm{g} / \mathrm{mL}$ cyclohexemide (Sigma) and protease inhibitor (Promega) in Polytron, and centrifuged for $10,000 \mathrm{xg}$ for $10 \mathrm{~min}$. A fraction of the supernatant $(50 \mu \mathrm{l})$ was separated for the analysis of total RNA and the remaining was seeded into a linear sucrose gradient.

\section{Polysomal profile}

The extract was fractionated in a linear gradient of $7-$ $47 \%$ sucrose prepared in $20 \mathrm{mM}$ Tris- $\mathrm{HCl}$ pH 7.5 (Sigma), $100 \mathrm{mM} \mathrm{KCl} \mathrm{(Sigma),} 10 \mathrm{mM} \mathrm{MgCl} 2$ (Sigma), 1 $\mathrm{mM}$ DTT (Sigma) and centrifuged by $2,5 \mathrm{~h}$ at $187,813 \mathrm{xg}$

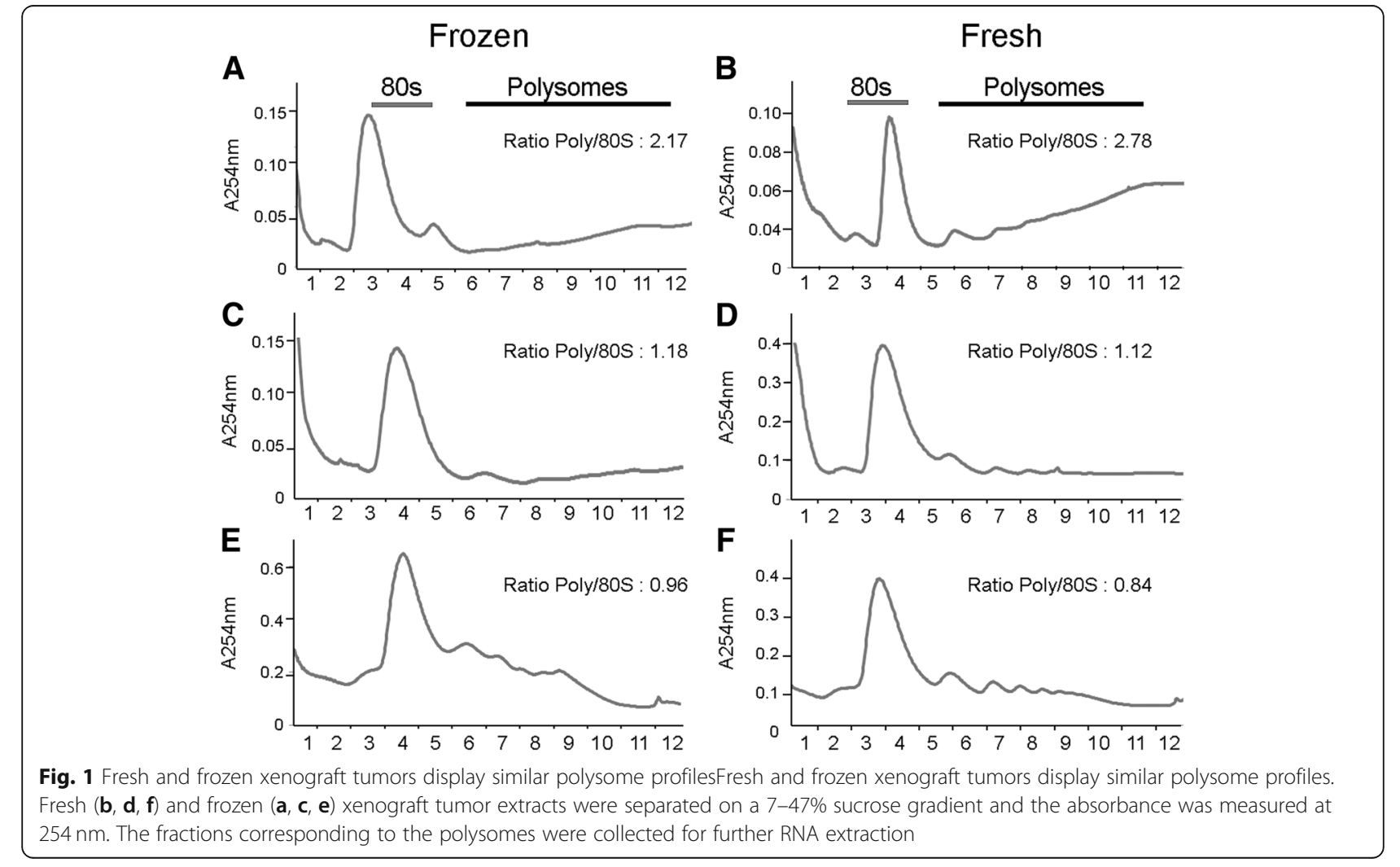



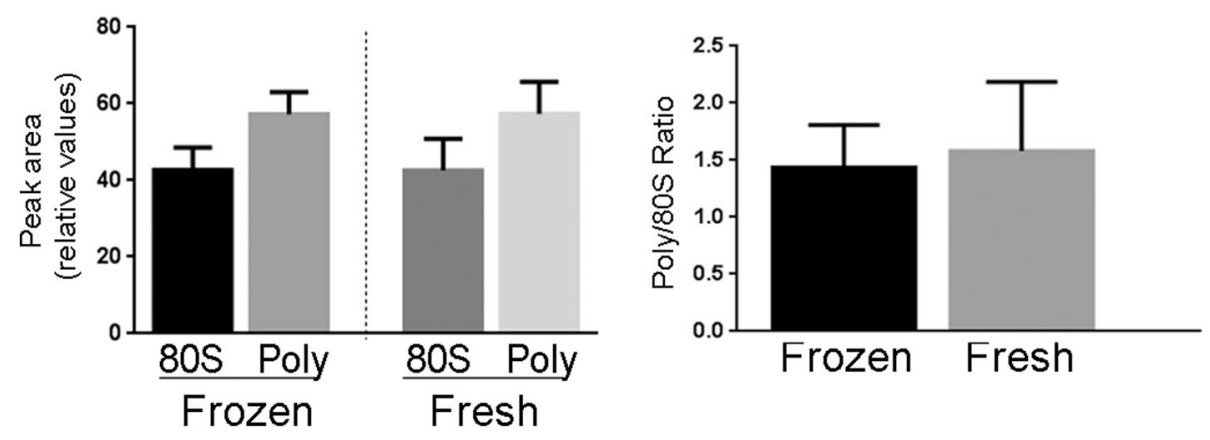

Fig. 2 Fresh and frozen xenograft tumors show equivalent translation ratesFresh and frozen xenograft tumors show equivalent translation rates. The area under the $80 \mathrm{~S}$ and polysome peaks was measured from fresh and frozen profiles. The peak area remained constant between fresh and frozen tissue. No statistically significant differences (Kruskall-Wallis test)

in an ultracentrifuge with the SW41Ti (Beckman Coulter) rotor at $4{ }^{\circ} \mathrm{C}$. The absorbance at $254 \mathrm{~nm}$ was detected in a continuous stream and the fractions $(1 \mathrm{ml}$ each) were collected. To measure the translational efficiency we compared the area under the curve from polysomal and 80s peaks from each group, using ImageJ software. To compare the groups we used One Way ANOVA test.

\section{mRNA extraction}

The RNA was extracted with Life Technologies TRIzol reagent according to manufacturer's instructions. To purify the messenger RNA from the samples, the Qiagen Oligote $^{\text {Tw }}$ kit was used, according to the protocol suggested by the manufacturer. All the extracted RNAs had RNA Integrity Number above 9 (Agilent Bioanalyzer).

\section{RNAseq}

For the sequencing, the Ion Personal Genome Machine $\left(\mathrm{PGM}^{\mathrm{m}}\right)$ System was used. The construction of the cDNA library follows the Ion Total RNA-Seq Kit v2 protocol. Briefly, RNA is mixed with spike-in internal controls. RNAs are fragmented with RNAse III for $3 \mathrm{~min}$, and then purified. The RNAs were subjected to a reverse transcriptase PCR for the construction of the cDNA library, which is amplified. The fragments are annealed to the specific beads of each kit by means of an emulsion PCR.

\section{Analysis}

The raw reads were filtered for contaminants (18S, 28S, 45S, 5S, C_elegans, Ciona_intestinalis, E.coli, Phix, S cerevisiae, SalmonellaTyphi, Shigellaflexneri, Yersinia_pestis, ALU, BACT1, BACT2, BACT3, BACT4, Virus) with Fastq-Screen 0.5.2 [10]. The single-end reads were mapped to the hg19 reference genome with TopHat v.2.0.2 [11], gene expression and differential expression analyses were done with Cuffdiff 2.2.1 [12]. For each comparison, the normalized FPKM expression of each gene was plotted, underscoring the agreement between the groups at this level.

\section{Results}

To evaluate the effect of freezing on tumor samples, glioblastoma cells (LN-229) were injected subcutaneously into 3 mice to obtain xenografted tumors. When the tumors reached $1 \mathrm{~cm}^{3}$ of volume, the animals were euthanized and the tumors removed and divided into two parts: half subjected to immediate extraction and the other half frozen for 15 days before processing. Both halves were subjected to polysomal separation (Fig. 1).

The translational efficiency of each sample was measured by the area below the $80 \mathrm{~S}$ peak curve and the polysome peak. It can be observed that the ratio between the $80 \mathrm{~S}$ and the polysomes peak remains constant between fresh and frozen tissues (Fig. 2), suggesting no dissociation of the polysomes.

To confirm that there is no alteration in gene expression levels in either total or polysome associated RNA given by the low-temperature storage, we performed RNAseq of total and polysome associated RNAs from one set of paired samples of fresh and frozen. RNAseq was successfully performed for all samples, with at least 5 million mappable reads per sample (Table 1). The

Table 1 Sequencing results for total and polysomal, fresh and frozen samples

\begin{tabular}{llllll}
\hline \# of reads & total fragments & after screen filter & filtered \% & mapped & mapped \% \\
\hline Total fresh & 9.664 .395 & 6.389 .255 & 33,89 & 5.364 .338 & 83,96 \\
Total frozen & 18.776 .432 & 14.213 .322 & 24,30 & 12.784 .196 & 89,95 \\
Poly fresh & 8.589 .258 & 6.064 .213 & 29,40 & 5.073 .423 \\
Poly frozen & 29.057 .797 & 17.194 .539 & 40,83 & 15.479 .920 & 83,66 \\
\hline
\end{tabular}



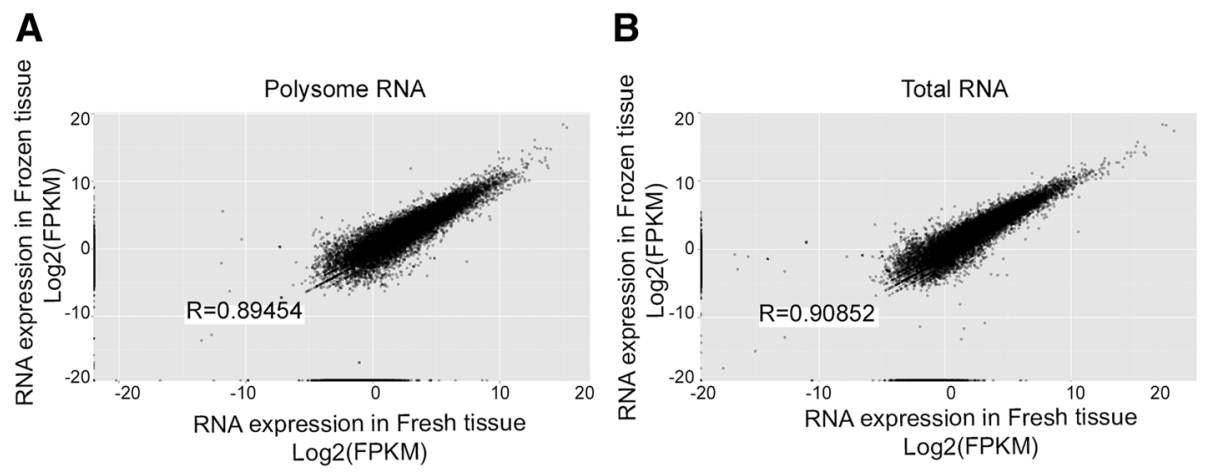

Fig. 3 Freezing does not affect identification of gene expression in total or polysome associated RNA. Gene expression (Log2FKPM) obtained from (a) polysome or (b) total RNASeq was used to plot the correlation between fresh and frozen samples

expression value of each mapped gene in fresh and frozen samples was plotted and a correlation index was calculated (Fig. 3). We observed a high concordance among fresh and frozen samples $(R>0.89)$, for both total and polysomal samples.

Together, our data indicate that storage in ultra-low temperature does not affect the polysomal structures, enabling the use of Biobank samples for the study of translational regulation.

\section{Discussion}

The study of translational control is essential to uncover dysregulation of several aspects involved in cancer development. For example in colorectal cancer in vitro models, more gene expression alterations are observed in the translational level than in transcriptional levels [13]. Also in in vitro models of epithelial-mesenchymal transition, a substantial amount of gene expression alterations were observed only at the translational level [14]. In addition, cellular stress frequently found in tumors, such as hypoxia, inhibits general translation while induces translation of a subset of genes important for stress response [15]. Thus, the determination of translational rates and differentially translated RNA in human samples has the potential to boost our knowledge of gene expression regulation in cancer.

However, the study of differentially translated genes in human samples depends on sample availability. Biobank storage is thus essential to improve sample collection, especially on rare tumors. Biobank storage is already a reality in several hospitals and cancer centers around the world, including the AC Camargo Cancer Center. One possible limitation of the identification of differentially translated genes, is the dependence of the conservation of the polysome structure, which could be affected by ultra-low temperature conservation. Fortunately, our data demonstrated that the freezing of the PDX tissues does not have an impact on translational rates and affects the detection of only a very small number of genes. Thus, we demonstrated the viability of ultra-low freezing stored samples for polysomal analysis, suggesting that this analysis is viable in Biobank stored tissues.

\section{Conclusions}

In this work we evaluated polysomal stability under freezing, demonstrating no interference of this storage method in translational rates or gene expression profiles for total and polysome associated RNA. Our data thus validate the use of Biobank stored samples for the study of differentially translated RNA.

\section{Abbreviations \\ 80S: Eukaryotic ribosomes; FPKM: Fragments Per Kilobase Million; GBM: Glioblastoma; HE: Hematoxylin and eosin staining; mRNA: Messenger RNA; PDX: Patient derived xenograft; RNA: Ribonucleic acid; RNAseq: RNA sequencing}

\section{Acknowledgments}

FAPESP fellowship to FCSL is gratefully acknowledged.

\section{Author contributions}

Conceptualization, FCSL, MR and GNMH; Methodology: FCSL, HB, EN, DMC; Writing: FCSL and GNMH. All authors read and approved the final manuscript.

\section{Funding}

This work was funded by Fundação de Amparo à Pesquisa do Estado de São Paulo (FAPESP) grants to GNMH (2018/17796-6) and M.R. (2015/15451-

3) and National Institute of Science and Technology in Oncogenomics and Therapeutic Innovation FAPESP 2014/509443-1, CNPq 465682/2014-6 e CAPES - 88887.136405/2017-00.

\section{Availability of data and materials}

Please contact Glaucia Noeli Maroso Hajj for data requests.

\section{Ethics approval and consent to participate}

Ethics Committee on Animal Use of the AC Camargo Cancer Center approved the study.

\section{Consent for publication}

All authors have read and approved the present manuscript.

Competing interests

The authors declare that they have no competing interests. 
Received: 8 May 2019 Accepted: 23 July 2019

Published online: 12 August 2019

\section{References}

1. Botti G, Franco R, Cantile M, Ciliberto G, Ascierto PA. Tumor biobanks in translational medicine. J Transl Med [Internet]. 2012;10(1):1 Available from: Journal of Translational Medicine.

2. Oosterhuis JW, Coebergh JW, Ben WE. Tumour banks: well-guarded treasures in the interest of patients. Nat Rev Cancer. 2003;3(1):73-7.

3. Bruce Alberts, Alexander Johnson, Julian Lewis, Martin Raff, Keith Roberts and PW. Molecular Biology of the Cell. 2002.

4. Kristensen AR, Gsponer J, Foster LJ. Protein synthesis rate is the predominant regulator of protein expression during differentiation. Mol Syst Biol. 2013;9:689.

5. Schwanhausser B, Busse D, Li N, Dittmar G, Schuchhardt J, Wolf J, et al. Global quantification of mammalian gene expression control. Nature. 2011; 473:337-42.

6. Bhat M, Robichaud N, Hulea L, Sonenberg N, Pelletier J, Topisirovic I. Targeting the translation machinery in cancer. Nat Rev Drug Discov. 2015 Apr;14(4):261-78.

7. Larsson O, Nadon R. Gene expression - time to change point of view? Biotechnol Genet Eng Rev. 2008;25:77-92.

8. Larsson O, Tian B, Sonenberg N. Toward a genome-wide landscape of translational control. Cold Spring Harb Perspect Biol [Internet]. 2013;5(1): a012302. Available from: http://cshperspectives.cshlp.org/content/5/1/a0123 02.long

9. Lupinacci FCS, Kuasne H, Roffé M, Vassalakis JA, da Silva FF, Santos TG, Andrade VP, Sanematsu P, Martins VR, Rogatto SR, Hajj GNM. Polysome Profiling of a Human Glioblastoma Reveals Intratumoral Heterogeneity. Int J Mol Sci. 2019;20(9). https://doi.org/10.3390/ijms20092177.

10. Wingett SW, Andrews S. FastQ screen: a tool for multi-genome mapping and quality control. F1000Research. 2018;7:1338.

11. Kim D, Pertea G, Trapnell C, Pimentel H, Kelley R, Salzberg SL. TopHat2: accurate alignment of transcriptomes in the presence of insertions, deletions and gene fusions. Genome Biol [lnternet]. 2013;14(4):R36. Available from: https://doi.org/10.1186/gb-2013-14-4-r36

12. Trapnell C, Hendrickson DG, Sauvageau M, Goff L, Rinn JL, Pachter L. Differential analysis of gene regulation at transcript resolution with RNA-seq. Nat Biotechnol [Internet]. 2012;31:46. Available from: https://doi.org/10.1038/ nbt.2450

13. Provenzani A, Fronza R, Loreni F, Pascale A, Amadio M, Quattrone A. Global alterations in mRNA polysomal recruitment in a cell model of colorectal cancer progression to metastasis. Carcinogenesis. 2006;27(7):1323-33.

14. Jechlinger $\mathrm{M}$, Grunert $\mathrm{S}$, Tamir IH, Janda E, Lüdemann $\mathrm{S}$, Waerner $\mathrm{T}$, et al. Expression profiling of epithelial plasticity in tumor progression. Oncogene. 2003;22(46):7155-69.

15. Blais JD, Filipenko V, Bi M, Heather P, Ron D, Koumenis C, et al. Activating transcription factor 4 is translationally regulated by hypoxic stress activating transcription factor 4 is translationally regulated by hypoxic stress. Mol Cellullar Biol. 2004;24(17):7469-82.

\section{Publisher's Note}

Springer Nature remains neutral with regard to jurisdictional claims in published maps and institutional affiliations. 